\title{
PERFORMANCE ASSESSMENT OF BASALT FRCM FOR THE CONFINEMENT OF CLAY BRICK MASONRY CYLINDERS
}

\author{
J. D’ANNA ${ }^{1^{*}}$, G. AMATO ${ }^{2}$, J. F. CHEN ${ }^{3}$, G. MINAFÒ ${ }^{1}$ AND L. LA MENDOLA ${ }^{1}$ \\ ${ }^{1}$ University of Palermo \\ Department of Engineering \\ Viale delle Scienze Ed. 8, Palermo (Italy) \\ e-mail: jennifer.danna@unipa.it (*corresponding author), giovanni.minafo@unipa.it, \\ lidia.lamendola@unipa.it \\ ${ }^{2}$ Queen's University Belfast (UK) \\ School of Natural and Built Environmental, David Keir Building \\ email: g.amato@qub.ac.uk; \\ ${ }^{3}$ Southern University of Science and Technology (China) \\ Department of Ocean Science and Engineering \\ email: chenjf3@sustech.edu.cn
}

Keywords: Masonry columns, FRCM, Basalt-fibre strengthening, Confinement, Experimental investigation

\begin{abstract}
Fibre Reinforced Cementitious Matrix (FRCM) composites have been proved to be a suitable strengthening material for masonry structures in the last years. Moreover, basalt fibres are increasingly used as reinforcement of composites as a more sustainable alternative to glass fibres. The goal of this work is to investigate the effectiveness of basalt FRCM to confine masonry circular columns. A total of eighteen clay brick masonry cylinders were tested in compression. The specimens were cored from two different masonry assemblies and wrapped with one or two layers of BFRCM composite. The stress-strain curves and the gains of strength and strain capacity of confined cylinders compared to the control specimens are reported together with a description of the failure modes.
\end{abstract}

\section{INTRODUCTION}

Recent earthquakes occurred in the Mediterranean area pointed out the high vulnerability of masonry building heritage, especially when structural details and quality of materials are not adequate. Masonry constitutes the main construction material of a wide part of the world building historical heritage and many of these structures need to be preserved for their cultural, historical and architectural values. Particularly vulnerable structural members are columns or piers, which usually sustain mainly axial loads. When a structure is affected by structural deterioration or undergoes change of designed use causing a variation of the acting compressive forces on columns, brittle crushing failure can arise. As a consequence, the need to repair and upgrade masonry columns constitutes an ongoing demand.

In this context, the use of external wraps made by composite materials represents one of the most popular techniques proven to be effective in upgrading the performance of weak masonry 
members ${ }^{[1,2]}$. The goal of this method is to increase the axial capacity and the local ductility of the material, producing a passive confinement action. In the last years growing attention has been paid to Fibre Reinforced Cementitious Matrix (FRCM) composites ${ }^{[4,5]}$, which proved to be suitable for strengthening masonry. The composite inorganic matrix makes the composite compatible to the masonry substrate and ensures durability in aggressive environmental conditions, vapour permeability and low sensitivity to high temperatures.

In regard to reinforcement, basalt textiles proved to be a promising alternative to the most common synthetic fabrics ${ }^{[6]}$, such as carbon or glass fibres.

Currently the majority of published experimental works on FRCM strengthening of masonry columns focuses on square/rectangular columns ${ }^{[1-8]}$. Although less common, testing of circular columns can provide useful data on the effect of pure confinement. Moreover, the effect of the number of reinforcing layers on the stress-strain response of FRCM-confined columns is investigated only by few studies ${ }^{[8]}$ as the most of experimental works consider only specimens reinforced with one or two grid plies ${ }^{[1-7]}$.

The present paper presents the results of a set of axial tests on clay brick masonry cylinders confined with BFRCM. A preliminary investigation was carried out on the mechanical properties of constituent materials of masonry and the strengthening system. The cylinders were assembled using two different brick arrangements in order to test the influence of the joints on the masonry capacity. The role of the reinforcing ratio was also studied by considering the confining effect of one or two layers of basalt FRCM. The results in terms of compressive
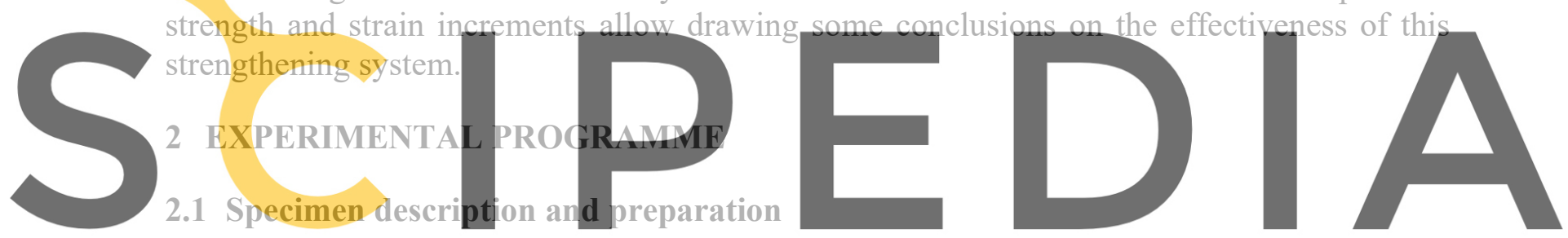

A total of eighteen clay brick masonry cylinders were prepared and tested under uniaxial

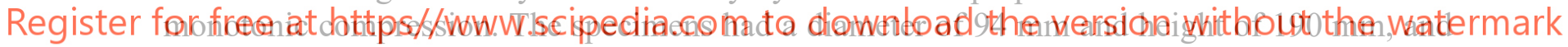
were cored from two different assembly schemes, Scheme I and Scheme II (see Fig. 1). Both schemes provided cylinders with three rows of pressed bricks and $8 \mathrm{~mm}$ thick mortar joints. Cylinders cored from Scheme I had only one vertical joint in the middle third (Fig. 1a) while cylinders cored from Scheme II had three staggered vertical joints, one at each level (Fig. 1b). The samples were cored after a curing period of 30 days and then wrapped with one or two BFRCM layers.

The tested specimens were very small in this study. It may be noted that what is important is the confinement pressure, not the surface to volume ratio. Existing studies on FRP-confined concrete columns have shown that there is no significant size effect for circular columns ${ }^{[9]}$. The only issue which might have some effect is that the overlapping zone is more significant compared with circumference in very small columns than larger ones, which would require further research.

Table 1 gives a summary of all the specimens. The tested cylinders were named as CN_SXL, where $\mathrm{C}$ stands for cylinder, $\mathrm{N}$ refers to the specimen number, $\mathrm{S}$ indicates the assembly scheme (W and $\mathrm{C}$ for Scheme I and Scheme II respectively), X refers to the number of confinement layers (1 or 2), L means layer. For unconfined samples, the last two letters were substituted by "Un". 
Table 1: Compressive tests on BFRCM-confined cylinders

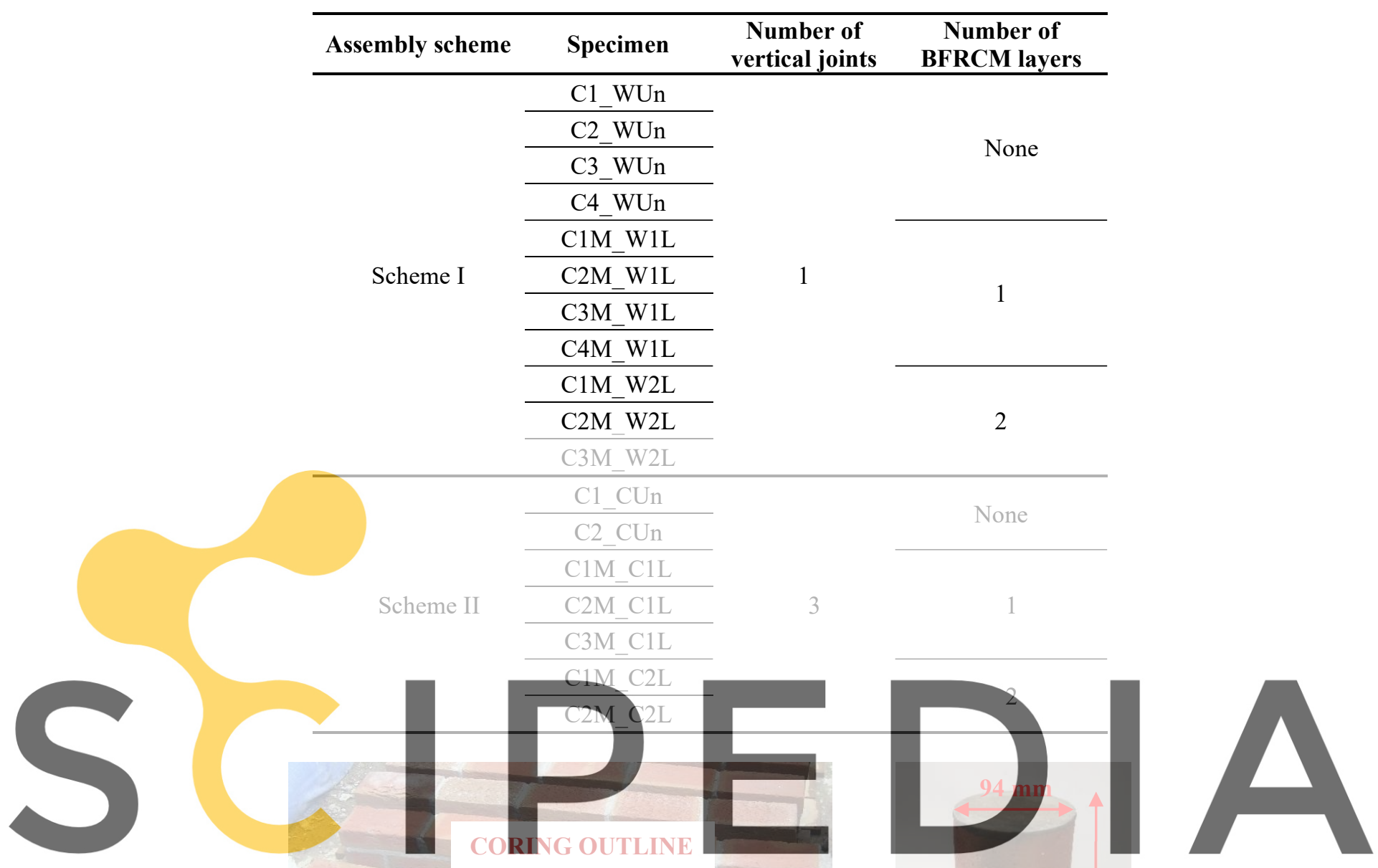

Register for free at https//www.scipedia.com to download the version without the watermark
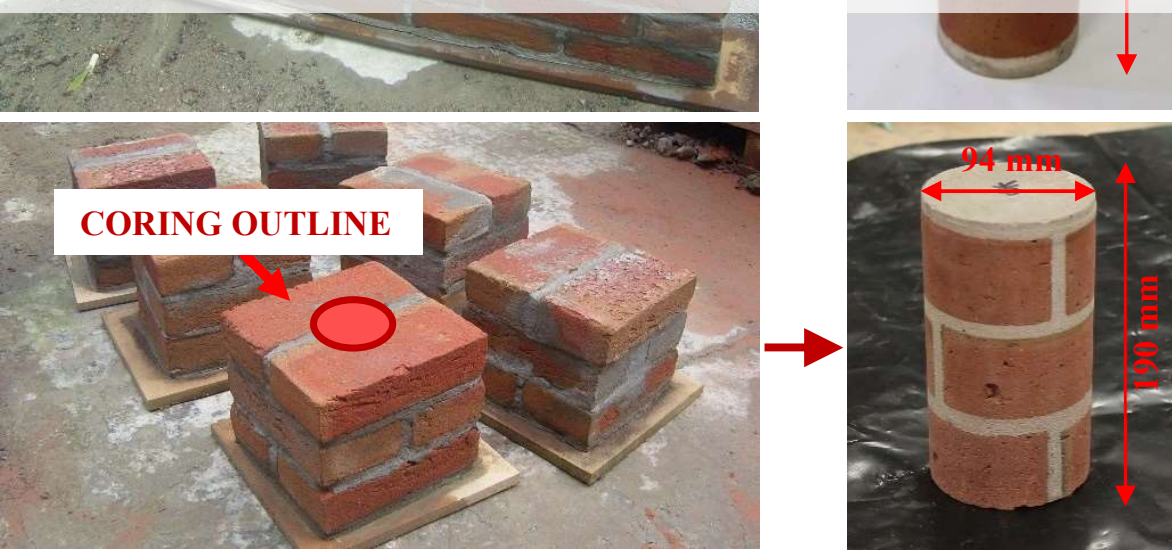

a)

Figure 1: Assembling schemes of cylinders: a) Scheme I (wall); b) Scheme II (column)

b) 


\subsection{Materials}

\subsubsection{Components of masonry}

Pressed bricks with nominal dimensions 50x100x210 mm were used for assembling walls and columns from which cylinders were cored. In order to characterize the mechanical behaviour of the clay brick units, six cubes with side equal to $50 \mathrm{~mm}$ were tested under uniaxial compression (Fig. 2a) according to EN 772-1 ${ }^{[10]}$. The bricks showed an average compressive strength equal to $42.53 \mathrm{MPa}(\mathrm{COV}=8.75 \%)$.

The mortar used for assembling walls and columns was composed of cement and sand, with a weight ratio of $1 / 5$. Water was added in order to reach the minimum workability. Three-point bending tests were performed on six standard 40x40x160 mm mortar prisms (Fig. 2b) and uniaxial compressive tests were carried out on obtained twelve halves, according to EN 1015$11^{[11]}$. The mortar had an average compressive strength equal to $20.93 \mathrm{MPa}(\mathrm{COV}=5.52 \%)$ and an average tensile strength equal to $5.33 \mathrm{MPa}(\mathrm{COV}=5.13 \%)$.

\subsubsection{BFRCM system and components}

The grid used to wrap the cylinders was a primed bidirectional grid, having nominal cell size of $6 \times 6 \mathrm{~mm}$ and equivalent thickness of $0.039 \mathrm{~mm}$. The nominal mechanical characteristics provided by the manufacturer were: unit tensile strength of $60 \mathrm{kN} / \mathrm{m}$, ultimate strain of $1.8 \%$ and Young's modulus of $89 \mathrm{GPa}$. To characterize the tensile behaviour of the basalt mesh,

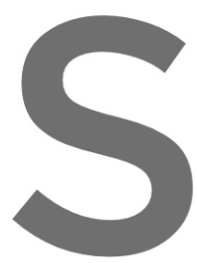
monotonic tensile tes ts were car to ISO 13934-1 [12]. The reported in Table 2, alo

The mortar used as ma enriched with short glas
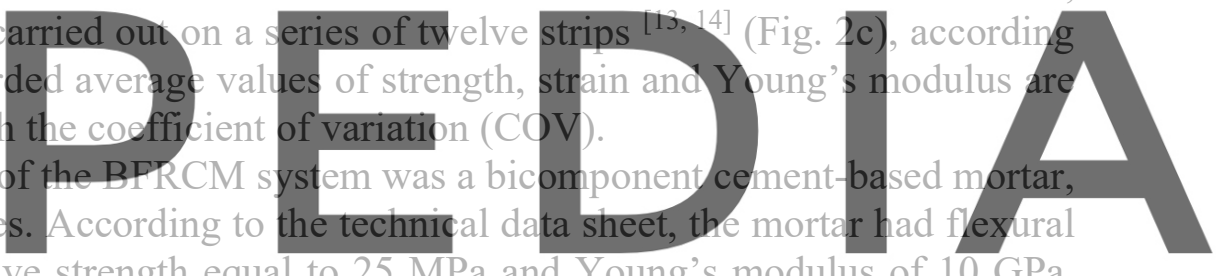
strength of $8 \mathrm{MPa}$, compressive strength equal to $25 \mathrm{MPa}$ and Young's modulus of $10 \mathrm{GPa}$.

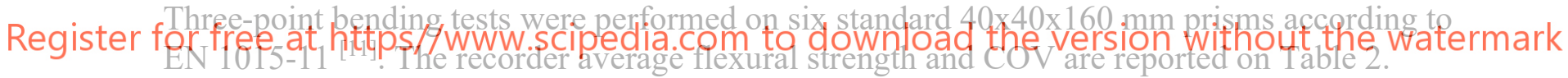

Additionally, the mechanical behaviour of the composite was characterized under tension.

Fourteen BFRCM coupons were manufactured using different reinforcement ratios, according to available regulations ${ }^{[15]}$. Specimens were tested under displacement control, with a rate of $0.2 \mathrm{~mm} / \mathrm{min}$ and using Digital Image Correlation (DIC) technique for recording the strain field $[13,14]$.

Table 2: Mechanical characterization of basalt grid and mortar matrix

\begin{tabular}{cccc}
\hline & BASALT GRID & MORTAR \\
\hline $\begin{array}{c}\text { Average Tensile } \\
\text { strength [MPa] } \\
\text { and COV }\end{array}$ & $\begin{array}{c}\text { Average Tensile } \\
\text { strain [\%] } \\
\text { and COV }\end{array}$ & $\begin{array}{c}\text { Average Elastic } \\
\text { modulus [GPa] } \\
\text { and COV }\end{array}$ & $\begin{array}{c}\text { Average Flexural } \\
\text { strength [MPa] } \\
\text { and COV }\end{array}$ \\
\hline 2045 & 2.55 & 81.91 & 7.18 \\
$10.55 \%$ & $8.21 \%$ & $3.48 \%$ & $2.80 \%$ \\
\hline
\end{tabular}



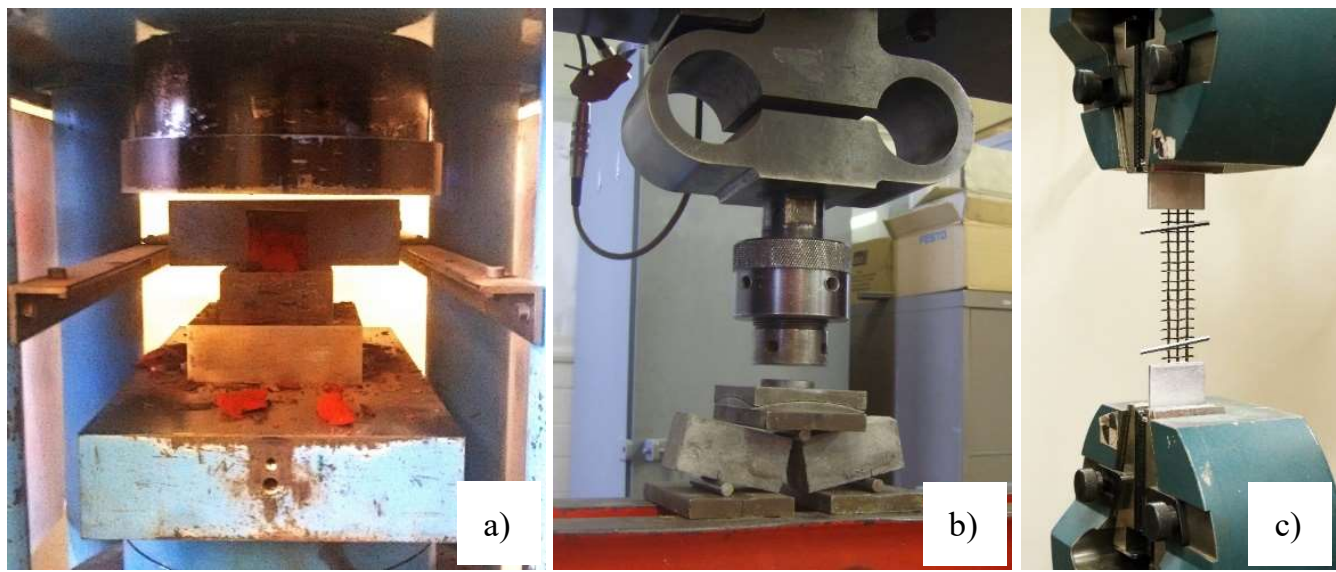

Figure 2: Characterization tests on components: a) compressive tests on brick cubes; b) three-point bending test on mortar; c) tensile test on basalt grid

\subsection{Test procedure and instrumentation for compression tests on cylinders}

A $600 \mathrm{kN}$ electro-hydraulic loading frame was used to perform monotonic compressive tests on the cylinders. Tests were carried out in displacement control, using a loading rate of 0.002 $\mathrm{mm} / \mathrm{sec}$, after applying three loading/unloading cycles under load control up to 40-50 kN.

Six Linear Voltage Differential Transducers (LVDTs) were installed, four to monitor the displacement of the upper loading platen and two at the lower platen (Fig. 3). In order to record the local axial strain in the middle hatf of the specimens, three extensometers connected to ty/c steel rings placed around the cylinders were also used.

Furthermore, the DIC technique was used to analyze the strain field on the su cylinders ${ }^{[14]}$. Outcones brevity.

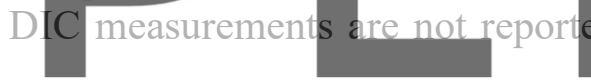

Register for free at https//www.scipedia.com to download the version without the watermark

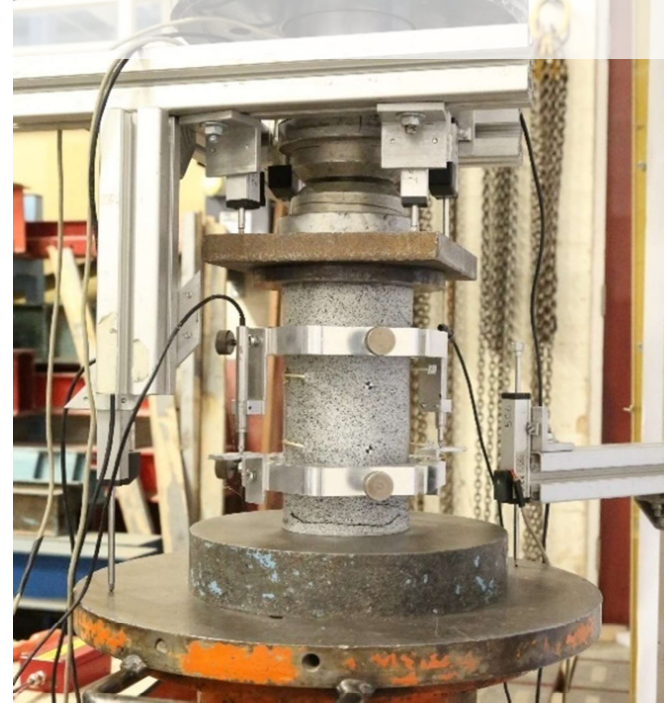

Figure 3: Test setup for compressive tests on masonry cylinders 


\section{RESULTS AND DISCUSSION}

\subsection{BFRCM system}

The average experimental results of the tensile tests on BFRCM coupons are summarized in Table 3 for the three series of samples reinforced with one, two and three layers respectively. In particular, the outcomes are presented with reference to the three stages typical of the response of FRCM composites tested under tension: un-cracked Stage I, crack development Stage II and cracked Stage III ${ }^{[13]}$.

Table 3: Average results of tensile tests on BFRCM coupons

\begin{tabular}{cccc}
\hline Series & Stage & Peak load [kN] & Strain [\%] \\
\hline \multirow{2}{*}{ 1 Layer } & I & 1234.11 & 0.030 \\
\cline { 2 - 4 } & II & 1398.03 & 1.019 \\
\cline { 2 - 4 } & III & 2054.93 & 2.322 \\
\hline \multirow{2}{*}{ 2 Layers } & I & 1448.22 & 0.035 \\
\cline { 2 - 4 } & II & 1855.26 & 0.448 \\
\hline \multirow{2}{*}{ 3 Layers } & III & 3538.20 & 1.912 \\
\cline { 2 - 4 } & I & 1437.38 & 0.044 \\
\hline
\end{tabular}

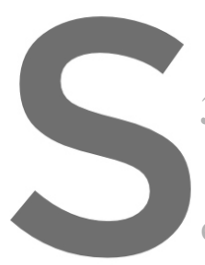

\section{IPED}

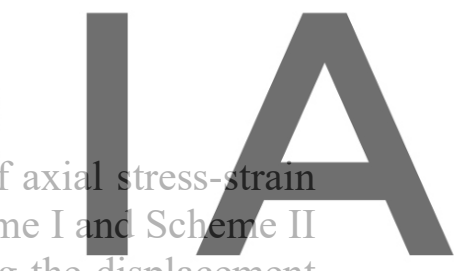
respectively. The axial strain up to the peak load was obtained considering the displacement

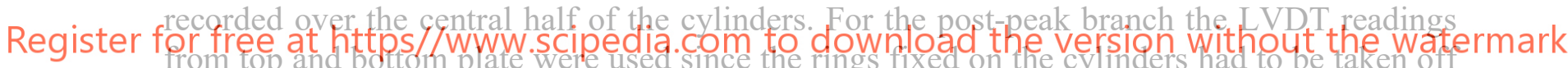
during the last part of the tests. For unconfined cylinders C1 WUn, C2 WUn, and C3 WUn, the strain was evaluated using the LVDTs on the top and bottom plates as the readings in the central area of the cylinders were lost during testing. This explains the different measured value of stiffness of these cylinders in Fig. 4a. The strains of these specimens were not taken into account for the calculation of $\varepsilon_{\mathrm{m} 0}$ and $\varepsilon_{\mathrm{m} 0 \mathrm{u}}$ in Table 4.

The stress-strain curves of unconfined cylinders present a brittle behaviour, characterized by an almost linear ascending branch and a steep load drop after the peak.

The stress-strain curves of BFRCM-confined cylinders show a linear branch followed by a stress drop due to the failure of the inner masonry core and the formation of first cracks in the external jacket. Afterwards, the curves show a new stress increase up to the peak, which is followed by a descending branch ending in a plateau region (Fig. 4). The full stress-strain curve of cylinder C3M_W2L is not available due to a technical problem during testing.

Table 4 reports the average peak axial stress $\left(f_{m 0}-f_{m c}\right)$, the axial strain at peak stress $\left(\varepsilon_{m 0}-\right.$ $\left.\varepsilon_{\mathrm{mc}}\right)$ and the ultimate axial strain corresponding to a $15 \%$ stress reduction with respect to the peak value $\left(\varepsilon_{\mathrm{m} 0 \mathrm{u}}-\varepsilon_{\mathrm{mcu}}\right)$ of tested cylinders, along with the COVs.

In the case of unconfined cylinders, the average peak stress values were $25.19 \mathrm{MPa}$ and 
19.85 MPa for Scheme I and Scheme II respectively, pointing out a considerable detrimental effect of the vertical mortar joints.

For one-layer confined cylinders, the average strength increases were equal to $27 \%$ and $66 \%$ for Scheme I and Scheme II specimens respectively, compared to unconfined cylinders. For cylinders confined with two BFRCM layers, the average strength gain was $38 \%$ for Scheme I and $85 \%$ for Scheme II. As expected, the effectiveness of BFRCM jacket was higher for the weakest masonry, i.e. in the case of Scheme II cylinders having three vertical joints.

Regarding the strain at peak stress, one-layer reinforced cylinders from Scheme I and Scheme II exhibited the same increase of average strain at peak stress, equal to $45 \%$, compared to control samples. Two-layer strengthened specimens from Scheme I showed an average increase of 57\%, while specimens from Scheme II presented an average strain gain of $75 \%$.

In terms of ultimate strain, cylinders from Scheme I showed an average ultimate strain increase of $72 \%$ and $97 \%$ for one and two-layer confined specimens respectively, in comparison to unconfined ones. For cylinders from Scheme II, the average ultimate strain increased by $96 \%$ and $121 \%$ respectively for one and two-layer reinforced specimens.
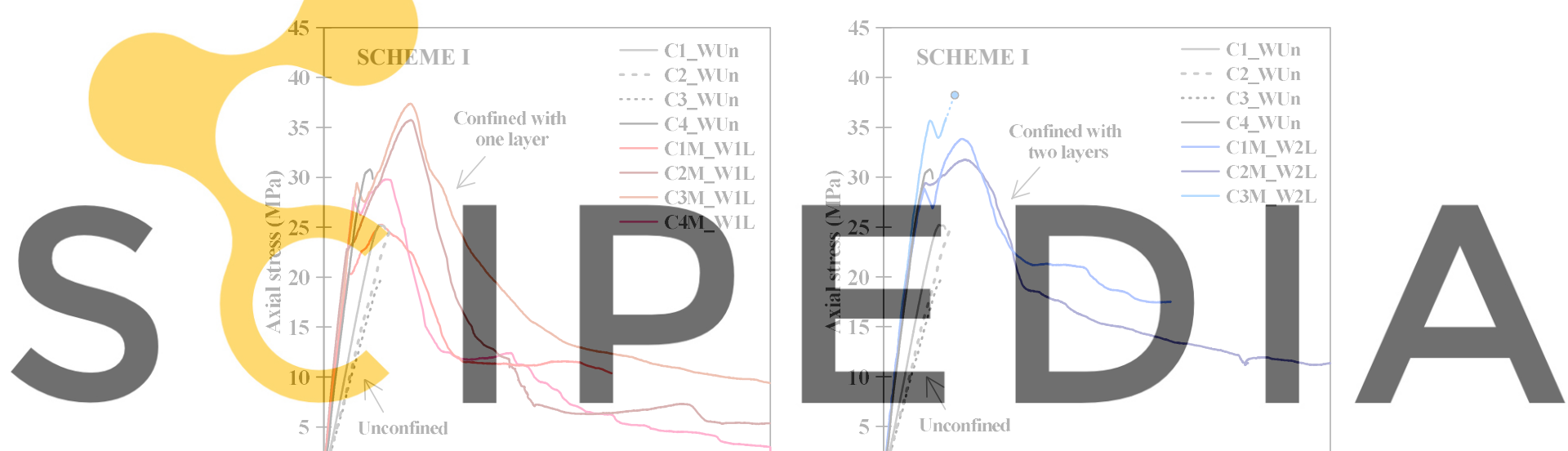

Register for free at https//WWW.scipedia.com to
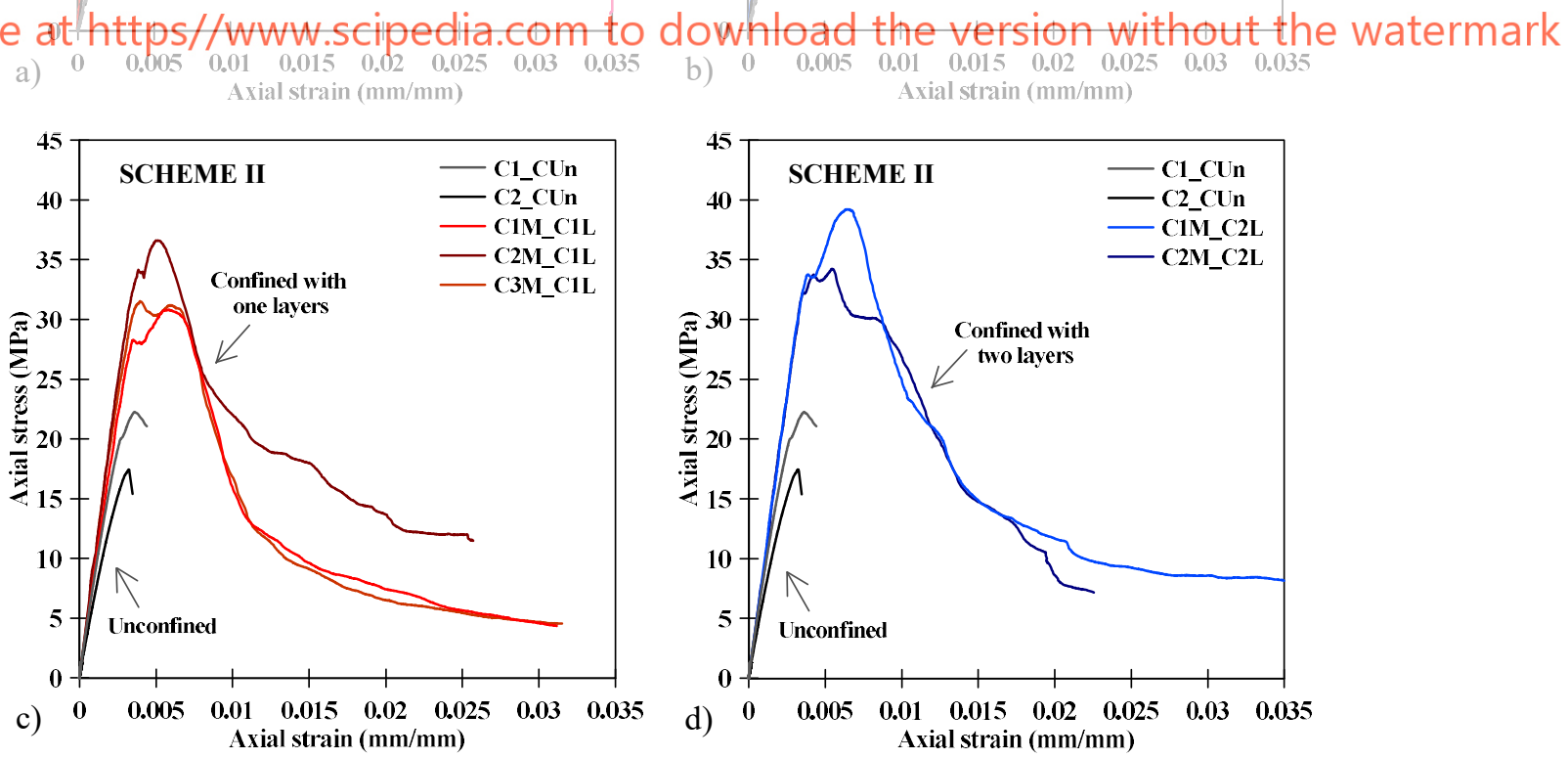

Figure 4: Stress-strain curves of masonry cylinders: a) Scheme I - 1 layer; b) Scheme I - 2 layers; c) Scheme II 1 layer; d) Scheme II - 2 layers 


\subsection{Failure modes of masonry cylinders}

Figure 5 presents unconfined and confined cylinders at the end of the compression tests.

As expected, the unconfined specimens showed a brittle behaviour and the failure was characterized by the formation of almost vertical cracks along the height. Vertical joints created preferential routes for the development of cracks and the failure involved crushing of masonry with spalling of material through the height of the cylinders (Fig. 5a and b).

Confined cylinders showed similar failure modes and no substantial difference was observed between the different schemes. In all the cases, the ultimate condition was reached by failure of the basalt textile. Vertical cracks developed for the entire length of the samples, producing detachment of the external mortar layer of the jacket in those parts and the loss of material in some areas (Fig. 5c and d).

Table 4: Average results of BFRCM-confined cylinders

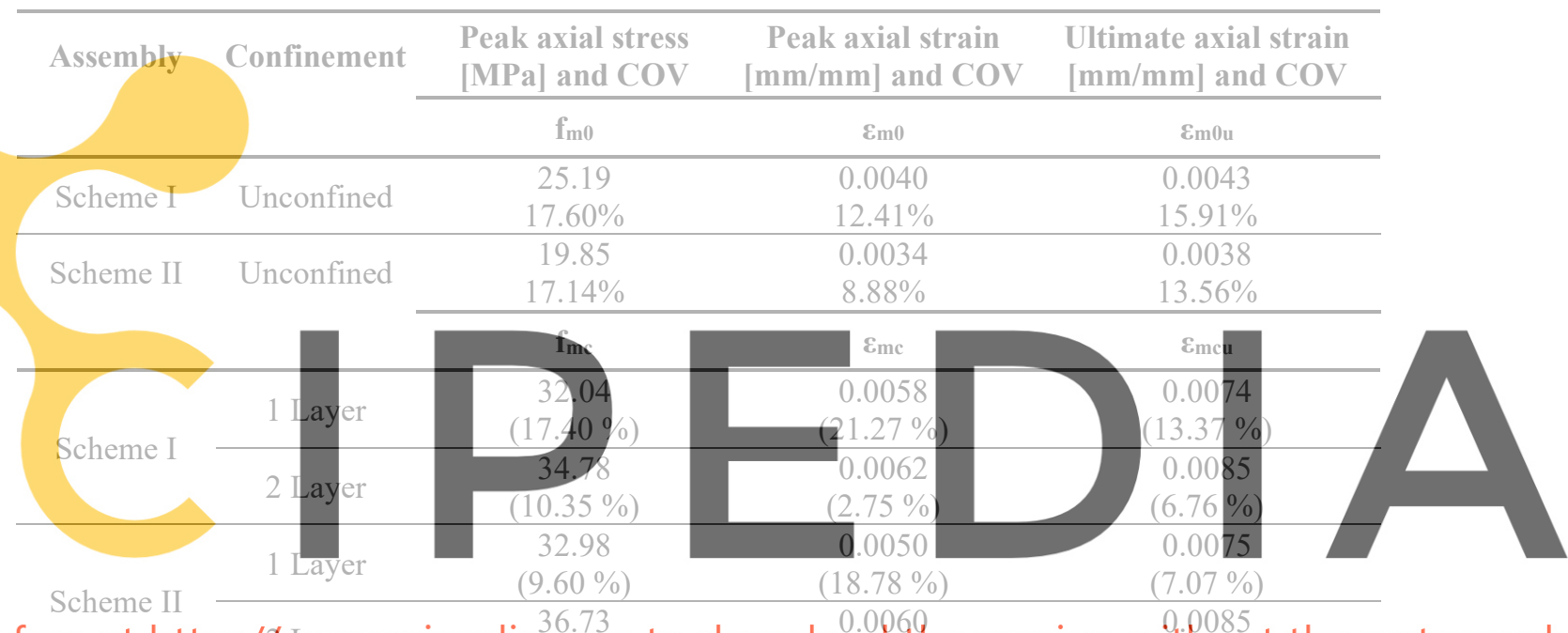
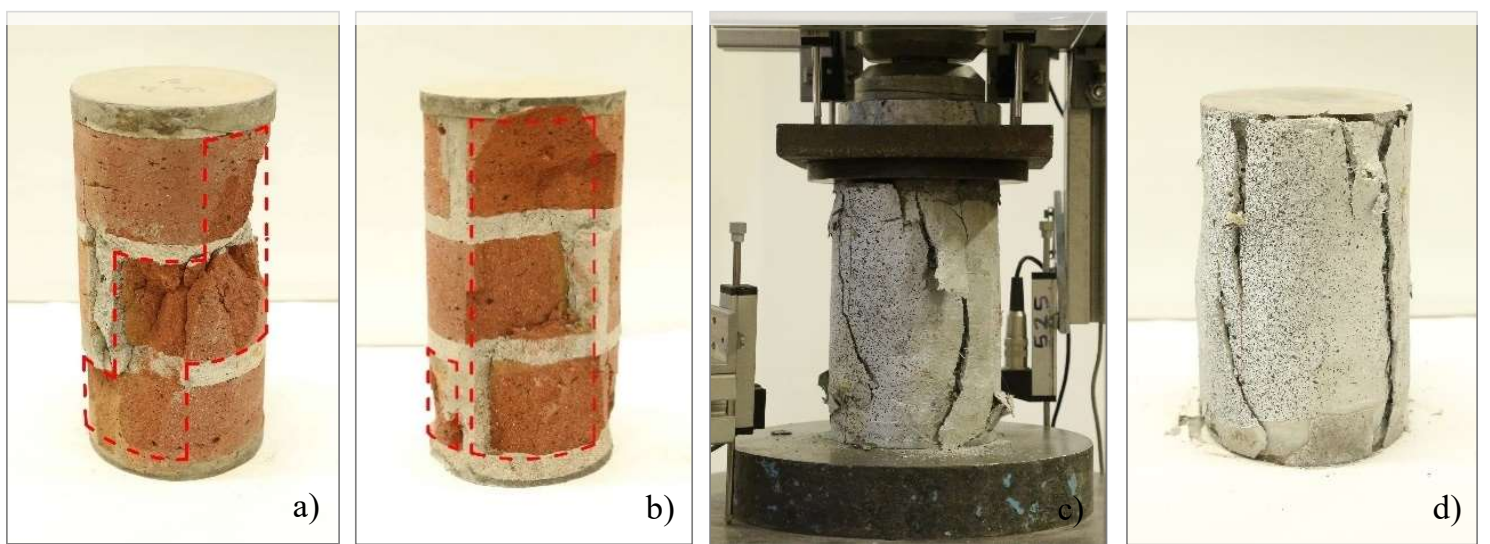

Figure 5: Cylinders after failure: a) unconfined (Scheme I); b) unconfined (Scheme II); c) one-layer BFRCMconfined (Scheme II); two-layer BRFCM-confined (Scheme II) 


\section{CONCLUSIONS}

This paper presented the results of an experimental study on small scale clay brick masonry cylinders, tested under axial compressive load. The cylinders had two different assembly schemes and were confined with one or two BFRCM layers. Considering the experimental results and for the range of variables examined, the following conclusions can be drawn:

- Unconfined cylinders with three vertical mortar joints (Scheme II) presented an average strength reduction of $20 \%$ compared with those having one vertical joint (Scheme I);

- For one-layer BFRCM-confined cylinders, the average strength increased $27 \%$ and $66 \%$ for Schemes I and II specimens respectively, compared to unconfined cylinders. Twolayer confined specimens had an average strength enhancement of 38\% for Scheme I and $85 \%$ for Scheme II, respectively;

- The confinement due to BFRCM increased considerably the ductility of the specimens. These last showed a softening branch in the compressive stress-strain curves;

- The ultimate condition of confined specimens was reached by failure of the basalt textile, highlighting that the full capacity of the fabric was exploited.

\section{REFERENCES}

[1] Micelli, F., Di Ludovico, M., Angiuli, R., Aiello, M. A. Experimental tests on full scale FRP/FRCM confined masonry columns subjected to axial load. Mater Struct (2014) 47(12):2081-2100

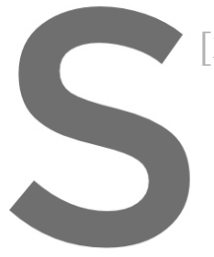

[2] Incerti, A., Vasiliu columns confined by on fibre reinforce conference on fibre pp. 14-16.
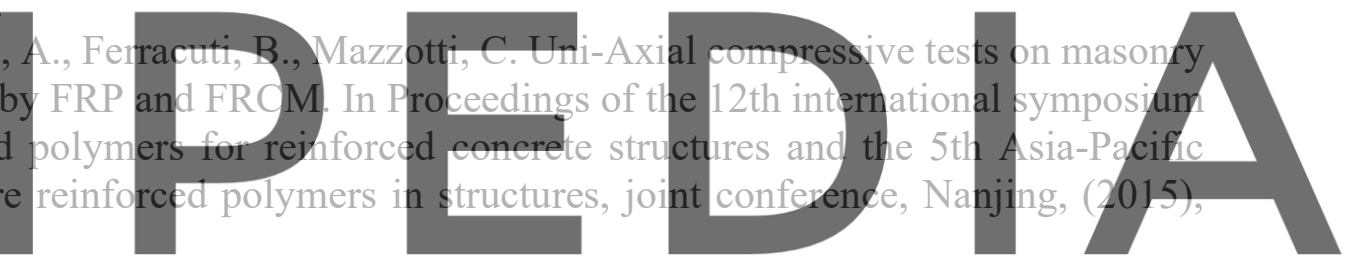

[3] Alotaibi, K. S. and Galal, K. Axial compressive behaviour of grouted concrete block

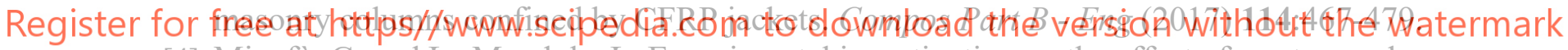

[4] Minafò, G. and La Mendola, L. Experimental investigation on the effect of mortar grade on the compressive behaviour of FRCM confined masonry columns. Compos Part B - Eng (2018) 146:1-12.

[5] Cascardi, A., Micelli, F., Aiello, M. A. FRCM-confined masonry columns: experimental investigation on the effect of the inorganic matrix properties. Constr Build Mater (2018) 186:811-825.

[6] Santandrea, M., Quartarone, G., Carloni, C., Gu, X. L. Confinement of masonry columns with steel and basalt FRCM composites. In Key Engineering Materials, Trans Tech Publications 747 (2017), pp. 342-349.

[7] Maddaloni, G., Cascardi, A., Balsamo, A., Di Ludovico, M., Micelli, F., Aiello, M. A., Prota, A. Confinement of full-scale masonry columns with FRCM systems. In Key Engineering Materials, Trans Tech Publications 747 (2017), pp. 374-381.

[8] Ombres, L. and Verre, S. Masonry columns strengthened with Steel Fabric Reinforced Cementitious Matrix (S-FRCM) jackets: experimental and numerical analysis. Measurement (2018) 127:238-245. 
[9] Guo, Y. C., Gao, W. Y., Zeng, J. J., Duan, Z. J., Ni, X. Y., \& Peng, K. D. Compressive behavior of FRP ring-confined concrete in circular columns: Effects of specimen size and a new design-oriented stress-strain model. Constr Build Mater (2019) 201:350-368.

[10] EN 772-1. Method of test for masonry units - Part 1: Determination of compressive strength (2011).

[11] EN 1015-11. Methods of test for mortar for masonry - Part 11: Determination of flexural and compressive strength of hardened mortar (1999).

[12] ISO 13934-1. Textiles - Tensile properties of fabrics - Part 1: Determination of maximum force and elongation at maximum force using the strip method. CEN - European Committee for Standardization (April 2013).

[13] D'Anna, J., Amato, G., Chen, J. F., Minafò, G., \& La Mendola, L. On the use of Digital Image Correlation (DIC) for evaluating the tensile behaviour of BFRCM strips. In Key Engineering Materials, Trans Tech Publications Ltd 817 (2019), pp. 377-384.

[14] D'Anna, J. Experimental investigation on the effectiveness of basalt-fibre strengthening systems for confining masonry elements (2019).

[15] ICC. AC434. Proposed Acceptance Criteria for Masonry and Concrete Strengthening Using Fibre-reinforced Cementitious Matrix (FRCM) Composite Systems. Whittier, CA: ICC-Evaluation Service (2013).
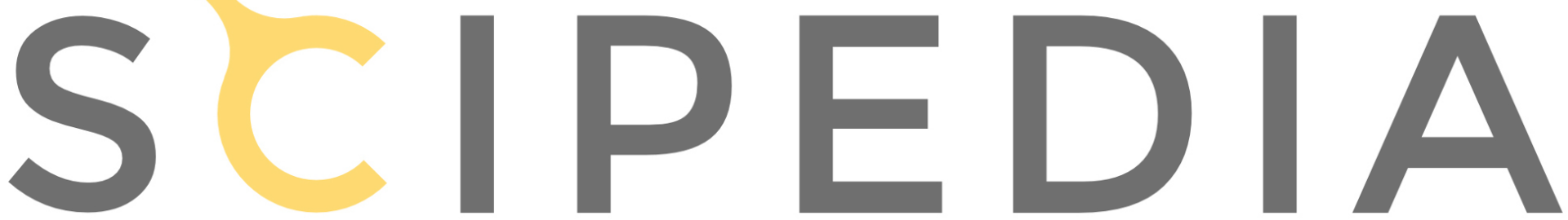

Register for free at https//www.scipedia.com to download the version without the watermark 